\title{
Um peregrino na busca da produção Intelectual argentina durante a Guerra Civil Espanhola (1936-1939)
}

\author{
Cristina Isabel Abreu Campolina de Sá ${ }^{1}$
}

BINNS, Niall. Argentina y la guerra civil española. La voz de los intelectuales. Madrid: Calambur, 2012. 820p.

Resenha recebida em: $31 / 08 / 2014$

Resenha aprovada para publicação em: 19/11/2014

Este livro faz parte da monumental coleção Hispanoamérica y la guerra civil española. Em 2012, Niall Binns brindou a comunidade acadêmica com dois extensos volumes que iluminam uma zona temática silenciada nos longos 36 anos da abominável ditadura de Francisco Franco: Ecuador y la guerra civil española. La voz de los intelectuales e Argentina y la guerra civil española. La voz de los intelectuales. Do segundo livro consistirá esta resenha. Sobre o conteúdo da coleção, registro de verdadeiro resgate documental, Binns informa que cada livro oferecerá uma

\begin{abstract}
espécie de radiografia do campo intelectual do país em questão entre os anos 1936 e 1939, no qual as lutas propriamente "intelectuais" conviviam com as vicissitudes da política interna e com as tensões internacionais.
\end{abstract}

Ao par disso, Binns esclarece que, em razão do contexto politizado dos anos 30, que mobilizou energias de diferentes setores das comunidades latino-americanas, no termo "intelectual" se inscrevem, momentaneamente, todas as pessoas que participaram do debate de ideias sobre a guerra civil através da palavra escrita. A partir da extrapolação do conceito clássico da figura do intelectual, Binns dá a entender que um núcleo fechado não daria conta de abranger o vivido, o contado e, sobretudo, os sentimentos gerados durante a guerra. Essa elasticidade também se aplica às origens dos

\footnotetext{
${ }^{1}$ Professora no Departamento de História da Universidade Federal de Minas Gerais (UFMG), Brasil. Email: cristinacampolina@ hotmail.com
}

\section{GANPHLAC}

Revista Eletrônica da ANPHLAC, ISSN 1679-1061, Nº. 17, p. 355-361, jul./dez. 2014. http://revista.anphlac.org.br/ 
intelectuais selecionados: argentinos residentes no país, argentinos que voltaram da Espanha à terra natal e espanhóis residentes na Argentina. Sobre o fundo desses diferentes diagnósticos foi escrita essa obra magistral.

$\mathrm{Na}$ primeira parte, intitulada Dolor de España. Intelectuais argentinos y la guerra civil española, o autor navega pelas águas turbulentas da década de 30, intercalando subcapítulos sobre a trágica história da Espanha em guerra com as distintas manifestações na ex-colônia espanhola. Inicia com uma referência à "Década Infame", na Argentina, então marcada pela ditadura militar, pelas eleições fraudulentas e pela repressão permanente aos opositores do regime: a esquerda em todas as suas expressões. A essa época, os intelectuais argentinos estavam inteiramente voltados para suas próprias definições literárias, que se prolongavam desde a década de 20 e se dividiam em tendências coletivas, como os grupos literários da Florida e, no outro extremo, os grupos de Boedo.

A proclamação da República Espanhola em 1931 foi o marco da mudança do olhar dos argentinos para a Espanha, até então com discreto fervor. Se essa boa nova indicava uma possibilidade futura para a Argentina, no que concerne à ideia de um país moderno e democrático, o levantamento dos militares rebeldes no Marrocos cinco anos depois, a eclosão da guerra fratricida, a luta desesperada dos espanhóis contra a ferocidade da extrema direita e a subsequente vitória do nacionalismo fascista significaram um retrocesso histórico sem precedentes. Em um desenho com traços fortes, Binns demonstra a extensão do drama da Espanha e sua ressonância, no arco temporal em que se deu a guerra, que "estremeceu a Argentina inteira", ou seja, a "Argentina vivia a guerra como se fosse sua". Independentemente do bando que a população apoiava, “a Espanha era outra vez a mãe-pátria, uma mãe que se dessangrava no prolongado e brutal parto para o futuro".

No formato de subcapítulos, como mencionado acima, Binns seleciona alguns temas e alguns episódios marcantes dentro do arco temporal em que se deu a guerra. $\mathrm{O}$ autor trata do intercâmbio cultural entre os dois países através da publicação de livros de viagens à Espanha escritos por autores argentinos, através da fundação da Instituición Cultural Española, responsável por convidar autores espanhóis do naipe de José Ortega y Gasset e Eugenio D’Ors para visitar a Argentina e da divulgação de obras espanholas

\section{GANPHLAC}

Revista Eletrônica da ANPHLAC, ISSN 1679-1061, No. 17, p. 355-361, jul./dez. 2014. http://revista.anphlac.org.br/ 
nas publicações da Revista Sur, de Victoria Ocampo. Por sua vez, os jornais de maior circulação no país, La Prensa e La Nación, publicavam sistematicamente, nos anos 30, artigos de renomados escritores espanhóis, inaugurando, em certo sentido, a prática do jornalismo paralelamente à literatura mais tradicional. Colaboraram em La Nación José Ortega y Gasset, Miguel de Unamuno, Rafael Altamira, Gregorio Marañón, Salvador de Madariaga, José María Salaverría, Luis Arasquitáin, Ramón Gómez de la Serna, entre outros. Em La Prensa, foram constantes as publicações de autores como Ramiro de Maeztu, Azorín, Jacinto Miquelarena e Corpus Braga. Questões que geraram polêmica, como a ideia de hispanidade defendida por Maeztu, foram amenizadas com o advento da República e a prometida modernização democrática.

Binns destaca a polarização política da sociedade entre os que apoiavam Franco e, do outro lado, os que alardeavam as virtudes da República. Pouco antes da rebelião militar, já havia sido fundada na Argentina uma Falange Espanhola, que atuou vivamente na propaganda a favor de Franco. Os católicos antiliberais, os setores conservadores, a imprensa nacionalista - Crisol, La Fronda, Bandera Argentina, La Razón e boa parte do governo vigente apoiaram irrestritamente os rebeldes. Enquanto isso, Buenos Aires fervia de solidariedade à República e à Frente Popular. Grande parte da ex-colônia espanhola simpatizava com a República, assim como inúmeros setores da população argentina que "viviam o conflito como se os afetasse diretamente, convencidos de que o resultado da guerra espanhola determinaria o futuro de seu próprio país". Foi constituída a Agrupación de Amigos da República Española, ligada à Embaixada, que em 1938 já contava com mais de 150 filiais. Em agosto de 1937, essa Agrupación juntou-se a treze outras agrupações já existentes com o mesmo objetivo. Socialistas, comunistas, anarquistas, trotskistas (esses dois últimos mais a favor da Revolução), parte da União Cívica Radical e outros partidos progressistas foram os baluartes na defesa da Espanha, que agonizava na luta contra o fascismo.

Para a maioria dos intelectuais clássicos, independentemente de sua ideologia, a dor da Espanha era também sua. A veneração à Mãe-Pátria, sempre custodiada pela direita tradicional, contaminou a atmosfera reticente quanto à antiga metrópole da esquerda nos anos de guerra. Houve intelectuais que viveram a guerra in loco, mas isso não significava ter de vivê-la para escrever sobre ela ou senti-la em toda a sua

\section{GANPHLAC}

Revista Eletrônica da ANPHLAC, ISSN 1679-1061, No. 17, p. 355-361, jul./dez. 2014. http://revista.anphlac.org.br/ 
intensidade. Da Espanha chegavam cartas, testemunhos jornalísticos, experiências vividas em hospitais e incontáveis relatos de toda natureza enviados por argentinos que viviam na Espanha ou que partiram da Argentina para encontrar a família na Península, ou mesmo para lutar pela República e também contra ela. Livros, crônicas, relatos, poesias, ensaios, poemas foram escritos durante e depois da guerra. Entre as obras citadas se encontram os testemunhos dos anarquistas Diego Abad de Santtillán, Valentín de Pedro, Jacobo Prince e Simón Radowitzky; e dos comunistas María Luisa Carnelli, Gregorio Bermann, Guillermo Delgado e do histórico presidente de Partido Comunista Argentino, Victorio Codovilla, apenas para citar alguns.

Havia também toda uma literatura de direita que não se furtou a essa solidariedade desse ponto de vista avesso. Na zona franquista destacaram-se os testemunhos de argentinos como o monsenhor Gustavo J. Franceschi, o senador Matías Sanchéz Hayes e Alejandro Sux, entre outros. O fato é que os intelectuais argentinos estiveram mobilizados durante o conflito em um comprometimento que ultrapassava qualquer orientação ideológica. A imprensa espanhola na Argentina também se posicionou a favor de Franco ou a favor da República. Entre os defensores de Franco situam-se os periódicos El Diario Español, Correo de Galicia, Fé Gallega e Patria Española. Favoráveis à república estavam Galicia, Noticiero Español, España Republicana, Iberia e Hispano. Como afirma o autor, "Nunca, en los países de Hispanoamérica se ha escrito tanto sobre España como en la época de 1936 a 1939”. A citação da frase de Álvaro Yanque evidencia a urgência dessa escrita: "Qué pluma de poeta no se levantó, airada, herida en el corazón por la bárbara tragédia?”.

Sem descanso durante todos os anos de guerra, a pluma dos poetas se levantaria em luto fechado para chorar a morte de Federico Garcia Lorca, em setembro de 1936. A notícia de sua morte teve um impacto único na comunidade intelectual argentina. Em 1931, Lorca, o poeta granadino, ocupou o destacado posto de embaixador da cultura na Argentina. Seu assassinato foi uma das provas do desprezo que Franco nutria pela cultura. Inúmeras foram as homenagens dedicadas ao poeta e dramaturgo espanhol, que deixou um rastro de luminosidade nos seis meses que morou em Buenos Aires. Durante as semanas seguintes à notícia da morte de tão ilustre personagem do mundo das letras, foram apresentados recitais poéticos e peças de teatro, de autoria do poeta, com

\section{GANPHLAC}

Revista Eletrônica da ANPHLAC, ISSN 1679-1061, Nº. 17, p. 355-361, jul./dez. 2014. http://revista.anphlac.org.br/ 
comovida recepção do público. No aniversário de sua morte, foi publicada em Buenos Aires uma Antología selecta de sua obra, com prólogo de Pablo Neruda e textos assinados pelo poeta chileno. A esses se agregaram textos de homenagem de Alfonso Reyes, Rafael Alberti, Antonio Machado, Carlos Luis Sáenz, Pablo Suero, Eugenio Navas, Horacio Raúl Klappenbach e J. Gómez Bas. Nessa atmosfera marcada por acontecimentos trágicos, pode-se afirmar que calar a voz dos seus contrários é a forma mais espúria de festejar a própria sobrevivência. Lorca foi fuzilado no início da guerra; sua voz, entretanto, jamais se calará.

No dia 20 de novembro, coincidentemente, morreram dois líderes espanhóis que empunhavam bandeiras diametralmente opostas: Buenaventura Durruti, famoso anarquista catalão, e José Antonio Primo de Rivera, fundador da Falange Espanhola e filho do ditador Miguel Primo de Rivera. A eles, Binns dedica dois subtítulos na primeira parte do livro, mostrando a conturbada trajetória política de Durruti, seus métodos revolucionários e as homenagens que lhe foram rendidas por toda a Espanha por ocasião de sua morte. Na Argentina, a morte de Durruti foi anunciada no mesmo momento em que acontecia uma homenagem a ele no teatro Rivera Indarte em Córdoba. Sobre a morte de Primo de Rivera, outra coincidência aconteceria 39 anos depois: no mesmo dia, morreria Francisco Franco. Curiosamente, a Falange de Primo de Rivera nunca alcançou um lugar de destaque no governo do ditador, os dois foram se aliar definitivamente na tumba dentro do Valle de los Caídos, onde, juntos, estão enterrados.

Binns discute a polêmica visita de Gregorio Marañón à Argentina em 1937. Marañón, importante médico e cientista espanhol, não inspirava confiança aos argentinos pela mudança de posição política seis meses depois da eclosão da guerra. Se, nos primeiros meses do conflito, Marañón declinou de um convite para ir ao Uruguai, alegando ser o dever de um espanhol ficar na Espanha, no final de 1936, foi para Paris, onde confessou publicamente seu equívoco em apoiar a República. Por essa declaração, Marañón foi duramente criticado, acusado de traidor e inimigo do povo espanhol. Recebido em Buenos Aires por Victoria Ocampo, a imprensa não poupou palavras para execrar a anfitriã, diretora da Revista Sur. Segundo Binns, "en médio de la guerra civil española era ya imposible seguir 'ejerciendo' de liberal”.

\section{GANPHLAC}

Revista Eletrônica da ANPHLAC, ISSN 1679-1061, Nº. 17, p. 355-361, jul./dez. 2014. http://revista.anphlac.org.br/ 
A destruição de Guernica e de outras cidades bombardeadas na Espanha inaugurara um tipo de guerra inédito na história: os civis eram mortos com se estivessem amontoados nas trincheiras e não nas ruas ou em suas próprias casas, destruídas pelas bombas dos fascistas, orquestradas pelos aviões alemães e italianos. A imprensa internacional não se calou perante a calamidade espanhola, a comoção era geral. Esse sombrio panorama foi retratado no quadro Guernica, pintado em Paris por Pablo Picasso, em 1937. Essa memória é reproduzida diariamente na retina dos visitantes do Museu Nacional Centro de Arte Reina Sofia, em Madri, desde setembro de 1981.

Outros temas são abordados por Binns, como: o caso Jacques Maritain; o congresso de escritores antifascistas em Valencia, em 1937; a missão falangista na Argentina, representada por Eduardo Marquina e Eugenio Montes, em outubro de 1937; o “indesejável” republicano Basilio Álvarez, em novembro de 1937; a visita à Argentina do socialista Indalecio Prieto, em janeiro de 1939. A primeira parte do livro é concluída com o subtítulo La guerra termina, febrero-abril 1939. Entre as comemorações e festejos de uma minoria de argentinos nacionalistas e espanhóis pró-franquistas, a frase que sintetiza o sentimento de derrota dos espanhóis, que bravamente enfrentaram os fascistas, foi proferida por Nicolás Olivari: "Nada nos consuela ya. Ninguna esperanza se nos promete".

Na segunda parte do livro, Binns apresenta a documentação que ratifica sua afirmativa sobre o impacto da guerra civil espanhola na Argentina e a proliferação de escritos, de toda ordem, sobre o fato. A paixão despertada pela Espanha em guerra deu um novo contorno às relações entre os dois países. $\mathrm{O}$ autor, com um fôlego e competência que o qualificam como um pesquisador de primeira ordem, organizou o vasto material, em mais de setecentas páginas, compostas por poemas, livros, histórias pessoais, fragmentos, panfletos, recortes de jornais, poesias, artigos, manifestos, entrevistas, cartas e muito mais, escritos por intelectuais que, se não o foram em vida, o foram efemeramente durante a guerra civil. A voz dos intelectuais argentinos através da rigorosa seleção de Binns oferece ao mundo acadêmico, aos estudiosos da literatura hispano-americana, aos historiadores e a outros núcleos interessados no tema da guerra civil uma obra de valor imprescindível nas bibliotecas. Como um intelectual que

\section{GANPHLAC}

Revista Eletrônica da ANPHLAC, ISSN 1679-1061, Nº. 17, p. 355-361, jul./dez. 2014. http://revista.anphlac.org.br/ 
extrapolou todos os limites do conceito, Binns inaugura uma nova concepção da categoria: o intelectual peregrino. A ele, os leitores, levados pela mão, devem uma das mais valiosas obras sobre a hedionda guerra. Ainda que não haja perdão para tamanha brutalidade, esta é amenizada pela beleza triste de poesias e ensaios escritos pelos intelectuais argentinos.

\section{CANPHLAC}

Revista Eletrônica da ANPHLAC, ISSN 1679-1061, Nº. 17, p. 355-361, jul./dez. 2014.

http://revista.anphlac.org.br/ 